point of the caravan routes between Egypt, Syria and Southern Arabia-owed its traditional foundation to Minos, and continued down to Roman times to worship the Cretan Zeus. The great cave on Mount Dicta, which was the legendary scene of the infancy of this indigenous divinity, to whom, as we have seen, the Palace of Knossos was also consecrated, has now been thoroughly explored by $\mathrm{Mr}$. Hogarth, and has produced a vast mass of votive relics illustrating the prehistoric culture of Crete from the earliest Metal Age onwards. The crevices of the stalactite columns of the lower part of the cave were found to have been utilised for the insertion of bronze offerings, especially miniature figures of the double axe, which was the particular symbol of this God. Many stone libation tables were also found representing the adaptation of early Egyptian forms, and among the votive bronzes an Egyptian figure of the god Amon $\mathrm{Ra}$, whose personality presents some points of affinity to the chief Cretan God. Another bronze from this site, a miniature chariot, drawn by an ox and a ram, has a special interest as an early example of a series of votive bronzes on wheels, in the shape of cars and tripods, supporting bowls, birds and other objects, which form a feature in the remains of a wide European zone during the Late Bronze and Early Iron Age. That their ultimate source was Egypt appears probable from the four-wheeled car with the silver boat of Queen Aah-hotep; but here again we see among Cretan remains what is probably the earliest European example of the class. Once more the archæo-

logical phenomena bring home to us the fact that we stand here at the meeting-place of the North and South wind.

ARTHUR J. Evans.

\section{THE ASCENT OF MOUNT ST. ELIAS} (ALASKA).1

$\mathrm{T}$

$\mathrm{HE}$ Italian original of this work was reviewed in our columns a short time ago (see NATURE, May 3), and we now welcome the English translation. In the preface we are informed that "the whole profit on the sale of the Italian edition, together with all royalties and rights on foreign editions, will be dedicated to an Insurance Fund for Italian Guides."

In its present garb the story of the expedition is told in simple and straightforward language, with only here and there an unaccustomed term to show its foreign origin ; e.g. "In September snow-storms continue alnost

1 “"The Ascent of Mount St. Elias (Alaska)," By H.R.H. Prince Luigi Amedeo di Savoia, Duke of the Abruzzi ; narrated by Filippo de Filippi : illustrated by Vittorio Sella : and translated by Signora Linda Villari with the author's supervision. Pp. xii $+24 \mathrm{I}$. 34 photogravure plates, 4 panoramic views, and $i 7$ illustrations in text. (Westminster Archibald Constable and Co., I900.)

No. $16[3$, voL. 62$]$ without cease" (p. ix.), and (in reference to rock-systems) "the different components of the soil of South Alaska are all stratified" (p. 232). The picturesque passages in the descriptions of the scenery have, however, lost their glow and read somewhat flat, as indeed can scarcely be avoided in a close translation. The distinctiveness of Prof. Israel C. Russell's name seems lost under the unfamiliar initials $J$. C., which are used throughout the book (except in the appendix, p. 232), although the full name is given correctly on p. 3 . Considering the high estimation in which the citizens of San Francisco hold their business energy, it is rather amusing to read $\mathrm{Dr}$. Filippi's impression that their city "being an agricultural centre, is very quiet and exempt from the feverish turmoil of the industrial Eastern States" (pp. 9-10).

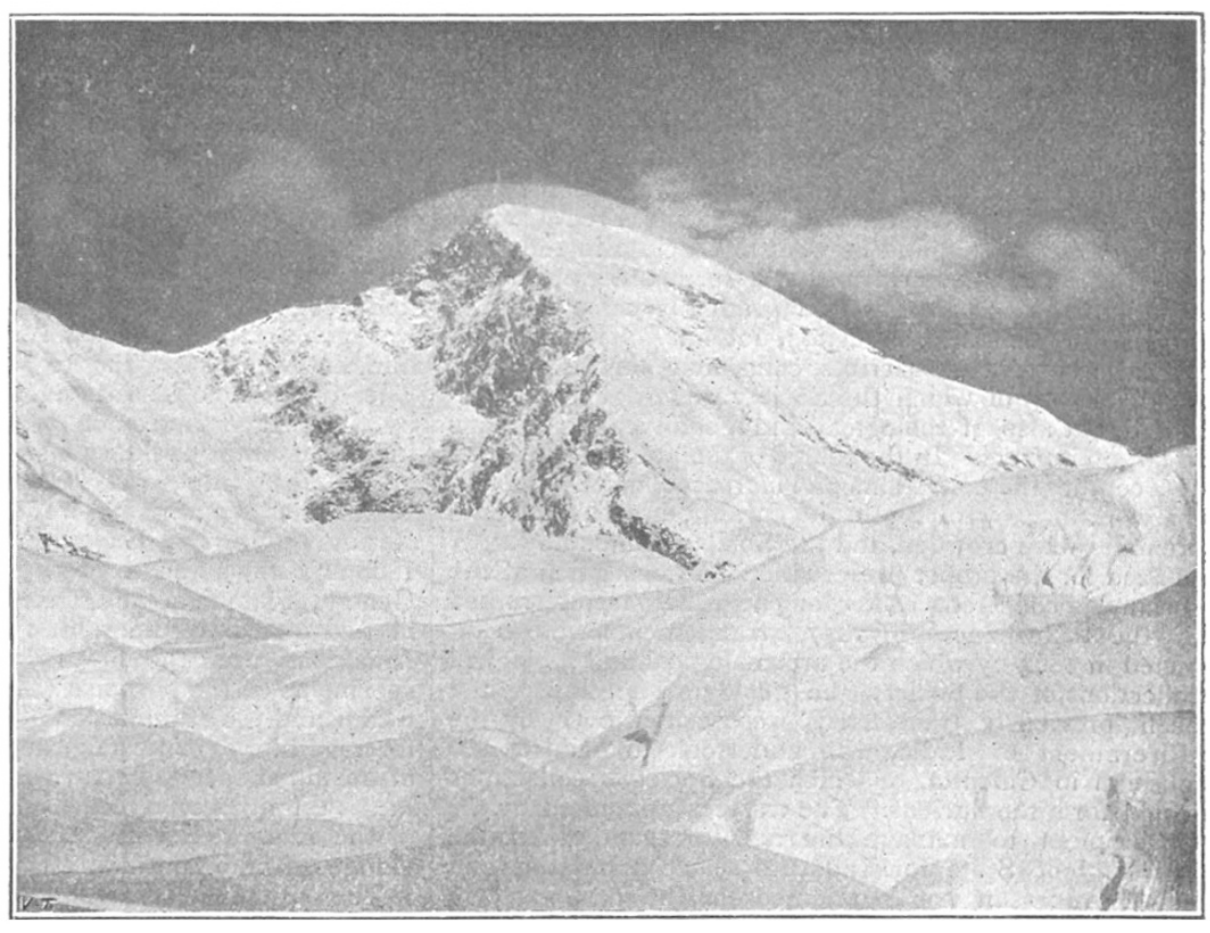

The profuse illustrations of the original are all reproduced; and in other respects this English edition is almost, but not quite, as sumptuous as its Italian forerunner. In fact so handsome is it, that in spite of the great mountaineering achievement which it chronicles, one cannot help harbouring, like a well-known essayist under similar circumstances, a lurking desire to strip it of its fine coat to re-clothe some ragged veteran of greater intrinsic consequence.

G. W. L.

JOHN ANDERSON, M.D., LL.D., F.R.S., ENC.

$\mathrm{BY}$ the death, on August 15, of Dr. John Anderson, in his sixty-seventh year, a serious loss has been inflicted on zoological science. Amongst the zoologists of this and other countries, Dr. Anderson was widely known and warmly esteemed. The particular branch of inquiry to which for many years before his death he had devoted himself, the investigation of the Vertebrata of Egypt, could only be successfully carried on by a naturalist who, in addition to experience in collecting, had both time and funds at his commiand, and who also possessed sufficient energy and tact to ensure the 
assistance of highly-placed Government officials. All these advantages Dr. Anderson combined in an unusual degree, and although it is to be hoped that the work he left unfinished will not be brought to an end by his death, there can be no question that the want of his guiding hand in the enterprise will be severely felt.

Dr. Anderson's scientific work consisted of two distinct parts. From 1865 to 1886 he was at the head of the Indian Museum, Calcutta, and chiefly engaged in the collection, arrangement and study of Indian and Burmese Vertebrata. After his retirement from India, in 1886 , the subject which occupied him principally, and of late years exclusively, was, as already mentioned, the study of the fauna inhabiting Egypt and the Nile valley.

He was the son of Thomas Anderson, a banker of Edinburgh, and was born on October 4, 1833. His elder brother, Dr. T. Anderson, was in the medical service of the East India Company, became well known as a botanist, and was for some years superintendent of the Botanical Gardens, near Calcutta. After passing through the medical course in the University of Edinburgh, John Anderson received a gold medal and the degree of Doctor of Medicine in I86I. For a couple of years he held the Professorship of Natural Science at the Free Church College, Edinburgh, and he went to Calcutta in 1864 .

His arrival in Calcutta was at a fortunate time. The Asiatic Society of Bengal had gradually come into the possession of a large collection, not only of the archæological remains, manuscripts, coins and similar objects, for the study of which the Society was originally estab. lished, but also of zoological and geological specimens in large numbers. In the course of the preceding quarter of a century the collections had increased, chiefly through the work of Edward Blyth, the curator, until the Society's premises were crowded, and the Society's funds no longer sufficed for the proper preservation and exhibition of the specimens collected. After long negotiations, interrupted by the disturbances of 1857 , arrangements were completed in 1864 by which the archæological and zoological collections of the Society (the geological specimens had been previously transferred). were taken over by the Government of India, who undertook to build a new museum in Calcutta, of which the Society's collections would form the nucleus. The trustees appointed by the Government to manage the new museum asked the Secretary of State for India to select a curator, and Dr. J. Anderson was nominated for the post early in I865. His status was changed, a few years later, to that of superintendent of the museum, and in addition to his museum work he became Professor of Comparative Anatomy at the Medical College, Calcutta. He held both offices until his retirement from India in I 886.

The time at which Dr. Anderson arrived in India was fortunate in another respect. It coincided with a great impulse given to Indian zoology by the publication of Jerdan's "Birds of India," the last volume of which appeared in 1864 , and with the presence in Calcutta of a larger number of men interested in the study of the fauna than were assembled there at any time before or since. Amongst these men were Jerdan himself, Ferdinand Stoliczka, Francis Day, and Valentine Ball, all of whom have now passed away. Probably at no time hás so much progress been made in the study of Indian Vertebrata as in the years $1864-74$, and in this work Dr. Anderson took an important part.

The new Indian Museum, which now towers over the other buildings of Chowringhee, was not ready for occupation till 1875, but meantime Dr. Anderson had been busily engaged in adding to the zoological collections and in getting them into order. One of his first tasks was the bringing together of an ethnological series, for which the conditions of Calcutta are favourable. Amongst other important additions made by him was that of a fine series of human skulls representing various Indian

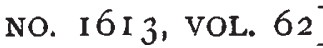

races. Another very valuable museum series brought together by him consisted of a good collection of Indian Chelonia ; skeletons, carapaces and stuffed specimens.

The work in Calcutta was interrupted by two important expeditions to Upper Burma and Yunnan, to both of which Dr. Anderson was attached as naturalist and medical officer. Both expeditions were designed to pass through China to Canton or Shanghai, but in neither case was it found practicable to carry out the original plan. The first expedition, commanded by Colonel $\mathrm{E}$. $\mathrm{B}$. Sladen, left Calcutta at the end of 1867 , proceeded as far as Momein in Yunnan, and returned to India in November I868; the second, under the command of Colonel Horace Browne, left in January 1875 , but was treacherously attacked by the Chinese before it had proceeded more than three marches beyond the Burmese frontier, and compelled to return, $\mathrm{Mr}$. Margery, of the Chinese Consular Service, who had been despatched to accompany the mission, and who had preceded it by a march, being murdered with several of his followers. The difficulties experienced by both missions from the time they crossed the frontier between Burma and China, and the opposition of the inhabitants of the country, seriously interfered with zoological observations, and the collection of specimens was generally impossible; but still some important additions were made to the previous knowledge of the fauna. A full account of the journey was given in Dr. Anderson's reports and in a work by him, entitled "Mandalay to Momein," published in 1876. The detailed observations on zoology, supplemented by important notes on some Indian and Burmese mammals and chelonians, were published in $1878-9$, under the title of "Anatomical and Zoological Researches, comprising an Account of the Zoological Results of the two Expeditions to Western Yunnan in I 868 and I875, and a Monograph of the two Cetacean Genera, Platanista and Orcella." The work appeared in two quarto volumes, one consisting of plates. Dr. Anderson was the first who succeeded in obtaining specimens of the porpoise (Orcella) inhabiting the Irrawaddi, and the examination of this previously undescribed form led him to make a thorough anatomical investigation of an allied species occurring in the Bay of Bengal and in the estuaries of rivers flowing into the bay, and also of the remarkable cetacean, Platanista, inhabiting the Ganges, Brahmaputra and Indus.

The only other important collecting expedition undertaken by Dr. Anderson during his tenure of the superintendentship of the Indian Museum was to Tenasserim and the Mergui Archipelago in $\mathrm{I} 88 \mathrm{I}-2$. This journey was chiefly, though by no means exclusively, undertaken for the collection of marine animals, and the descriptions of the results, to which several naturalists contributed, were published first in the Journal of the Linnean Society, and subsequently as a separate reprint in two volumes, under the title of "Contributions to the Fauna of Mergui and its Archipelago." This appeared in I889. Dr. Anderson's share was the description of the Vertebrata and an account of the Selungs-a curious tribe inhabiting some of the islands; but in connection with his visit to Mergui, and as part of a general description of the fauna which he had at first proposed to publish, he prepared an account of the history of Tenasserim, formerly belonging to Siam. This historical résumé, which deals especially with British commercial and political intercourse with Siamese and Burmese ports, was compiled mainly from the manuscript records of the East India Company, preserved in the library of the India Office, and was published in I 889 in a separate volume, entitled " English Intercourse with Siam." The book forms a well-written and interesting chapter of the history of British progress in Southern Asia.

Besides the works already mentioned and many papers, descriptive of mammalia and reptiles, which 
were published in the Journal of the Asiatic Society of Bengal and in the Proceedings of the Zoological Society of London, Dr. Anderson wrote two catalogues on very different subjects for the museum under his charge in Calcutta. Of these, one was the first part of the "Catalogue of Mammals," published in $188 \mathrm{I}$, the other the "Catalogue and Handbook of the Archæological Collection" which appeared in 1883 .

Dr. Anderson was elected a Fellow of the Royal Society in 1879 , and retired from the Indian Service in 1886. He had married a few years previously, and after retiring he travelled with his wife to Japan. Finally he settled in London, but for the remainder of his life his health was somewhat precarious, and he passed several winters in Egypt. Here he took up the study of the mammals and reptiles, which had received but scant attention since the early part of the century, when the great and superbly illustrated French work on Egypt appeared-a work which, brilliantly begun by Savigny and others, was never adequately completed.

To the work of collecting, examining, figuring and describing the Mammalia, Reptilia and Batrachia of Egypt, the later part of Dr. Anderson's life, when he was well enough for work, was mainly devoted. He also paid some attention to the fauna of the neighbouring countries, and in 1898 published "A Contribution to the Herpetology of Arabia," founded on the collections of the late Mr. J. T. Bent and others. The first part of the important work he had intended to produce on the zoology of Egypt, containing an account of the physical features of the country and descriptions of the Reptilia and Batrachia, appeared in 1898. It is a fine quarto volume with excellent figures, many of them coloured. He had made large collections and notes for the volume on Mammalia, and these it is hoped will be published in due course.

One of the last undertakings in which Dr. Anderson engaged, as soon as the Upper Nile valley was once more thrown open to civilisation, was the systematic collection and description of the fish inhabiting the river and its tributaries. That this important work (of which a notice appeared in NATURE of February 23,1899 ) is now being carried out with warm interest and assistance from the Egyptian Government, must be attributed to Dr. Anderson's foresight, zeal and skilful advocacy. Both in our Indian Empire and in North-eastern Africa, Dr. Anderson contributed much to the solution of one of the chief biological questions of the present day, an accurate knowledge of the distribution of animal life.

W. T. B.

\section{NOTES.}

A NEW instance of the want of encouragement, and often opposition, which scientific work receives in this country is given by Major Ronald Ross in a letter in Monday's Times. It appears from a correspondence just published, that in 1898 the Secretary of State for India refused to permit officers and soldiers to undergo voluntary inoculation against typhoid. It is known to our readers that Dr. Wright, professor of pathology at Netley, elaborated the system of inoculation against typhoid so long ago as 1896 . The treatment is based on the soundest scientific principles, and substantial evidence of its value as a preventive measure had been obtained by laboratory experiments. It is entirely free from danger, and there would have been no diffculty in obtaining numerous soldiers to undergo inoculation with Dr. Wright's typhoid vaccine. From the results of the inoculations which might thus have been made three years ago, results would have been obtained which could have been utilised in the recent war in South Africa, and might have been the means of saving hundreds of lives. But unfortunately for the army as well as for science, officers and soldiers appear to have been forbidden

NO. 16 I 3 , vOL. 62 ] to submit themselves for inoculation. In other words, a real success against disease might have been scored, and in any case the information gained would have been of value in making further efforts to diminish mortality from typhoid, but the officials who should have done everything in their power to assist the work, deliberately stopped it by hampering the freedom of the persons who would most benefit by the treatment. It is difficult to understand this singular action, and Major Ross has done a public service by directing attention to it.

IT was announced in NATURE several months ago (p. 230) that Dr. L. Sambon and Dr. G. C. Low, of the London School of Tropical Medicine, had arranged to live from May to the end of October-that is, during the malarial season-in a part of the Roman Campagna, near Ostia, where scarcely a person spends a night without contracting malarial fever of a virulent type. Na quinine or other drug was to be taken as a precautionary measure, but the investigators were to live in a mosquito-proof hut from an hour before sunset to an hour after sunrise, so as to avoid being bitten by mosquitoes, which only feed during the night. The experiment was planned to test the reality of the connection between malaria and mosquitoes, and we learn from the British Medical Journal that it has been most successful. On September 13, Prof. Grassi visited the residence of the investigators with several other men of science, and gave his testimony as to the value of the experiment in the following telegram to Dr. Manson : "Assembled in British mosquito-proof hut, having verified perfect health experimenters amongst malarial stricken inhabitants, I salute Manson who first formulated mosquito malarial theory.-Grassi." So far as the experiment has gone, therefore, the result is entirely satisfactory, and affords the strongest support to the mosquito theory of malaria. Additional evidence is given by Dr. Elliott, a member of the Liverpool expedition sent to Nigeria some time agu to investigate the subject of malarial fever, who has recently returned to this country. He reports that the members of the expedition have been perfectly well, although they have spent four months in some of the most malarious spots. They lived practically amongst marshes and other places hitherto supposed to be the most deadly, and they attribute their immunity to the careful use of mosquito nets at night.

ANOTHER experiment arranged in connection with their malarial investigation in the Campagna is described in the British Medical Journal. Drs. Sambon and Low have shown that by avoiding mosquitoes they avoid malaria ; but this is, after all, only negative evidence, and its fuil value can only be appreciated in connection with the actual production of malaria in a healthy person in this country by the bites of mosquitoes containing the germ of the disease. This evidence is now forthcoming. We learn from our contemporary that a consignment of mosquitoes which had been fed on the blood of a sufferer from malaria in Rome, under the direction of Prof. Bastianelli, was received in London early in July. A son of Dr. Manson, who offered himself as a subject for experiment, allowed himself to be bitten by these insects, and, though he has never been in a malarious country since he was a child, he is now suffering from well-marked malarial infection of double tertian type, and microscopical examination shows the presence of numerous parasites in his blood. Full details of the experiments will be published in due course; meanwhile, they must be regarded as affording the most striking confirmation of the transmission of malaria by mosquito bites that has yet been obtained.

DR. L. A. BAUER, in charge of magnetic work of the U.S. Coast and Geodetic Survey, has gone to Alaska and to the Hawaiian Islands, in order to select the sites for the magnetic observatories in those regions. The principal or standard 